\title{
A voz do professor acerca do uso das novas tecnologias nas escolas
}

\author{
Klever Corrente Silva ${ }^{1}$
}

Alcinéia de Souza Silva ${ }^{2}$

\section{Resumo}

O advento das novas tecnologias traz um novo paradigma técnico-econômico que impacta em diferentes esferas da vida social. Mas quais são as percepçóes e experiências dos professores em relação às novas tecnologias e ao trabalho pedagógico? Quais são os desafios impostos aos espaços educativos diante desse novo paradigma? Que reconfiguraçóes precisam ocorrer nas escolas para atender às necessidades da sociedade tecnológica? Por que e como as novas tecnologias podem ser encaradas como potencializadoras e facilitadoras do processo de ensino-aprendizagem? É na busca dessas respostas que este trabalho investiga e analisa a compreensão que professores têm sobre o uso das novas tecnologias nas escolas. A partir de uma pesquisa empírica com um grupo de professores de uma turma de Pós-Graduação Stricto Sensu em Educação da Universidade de Brasília, os resultados evidenciaram a importância da incorporação das novas tecnologias e de métodos apropriados para fazer frente às demandas do mundo midiático.

Palavras-chave: novas tecnologias; professor; escola.

\section{The teacher's voice about the use of new technologies in schools}

\section{Abstract}

The arrival of new technologies brings forth a new technical and economical paradigm which impacts different areas of social life. What are, however, the experiences and perceptions of teachers regarding new technologies and pedagogical work? What are the challenges that are brought to educational environments with this new paradigm? What reconfigurations need to occur in schools so that the needs of technological society are met? Why and how can new technologies be seen as enhancers and facilitators of the learning process? It is in the search of these answers that this study investigates and analyzes the understanding that teachers have about the use of the new technologies in the schools, from an empirical research with a group of teachers who attend the Stricto Sensu Post-Graduate in Education at University of Brasilia. The results showed the importance of incorporating new technologies and appropriate methods to answer to the demands of the media world.

Keywords: new technologies; teacher; school.

1 Mestre em Educação pela Universidade de Brasília e professor na Secretaria de Estado de Educação do Distrito Federal/DF. E-mail: klever.cs@gmail.com.

2 Doutoranda em Geografia pela Universidade de Brasília e Professora da Secretaria Municipal de Educação de Formosa/GO. E-mail: alcineias32@gmail.com. 


\section{Introdução}

O mundo está em constante processo de transformação, que cada vez mais tem se acelerado, pois a engenhosidade humana e a capacidade de inovar têm trazido mudanças profundas para a vida em sociedade. Um movimento de reconfiguração de tempos e espaços geográficos tem ocorrido, precipuamente, por conta do avanço tecnológico.

As transformaçóes advindas da incorporação de novas tecnologias vêm afetando as diversas esferas da vida em sociedade. Existe uma nova lógica para as atividades produtivas e sociais: expande-se o processo de globalização, há mais flexibilidade, demandam-se novas formas de organização, ampliam-se as possibilidades funcionais. $\mathrm{O}$ cerne desse novo paradigma técnico-econômico são as novas tecnologias, mas o potencial delas, em sua plenitude, só pode efetivamente ocorrer se paralelamente acontecerem mudanças sociais e institucionais nos sistemas de ensino e de formação (CARVALHO, 2003).

A reestruturação social está em curso e traz um novo perfil e novo estilo de comportamento, pois as pessoas se informam, interagem e se comunicam de diferentes formas. $\mathrm{O}$ mundo mudou, a sociedade mudou, portanto, espera-se que as instituiçóes de ensino também mudem e que elas acompanhem e se integrem a esse movimento dinâmico e utilizem as potencialidades das novas tecnologias para reformular as formas de ensinar e de aprender.

A educação tem sido considerada um fator fundamental e estratégico, sem o qual não se pode fazer frente aos desafios postos pelo novo paradigma (CARVALHO, 2003). O mundo tecnológico é atrativo, envolve e motiva grande parte do dia dos indivíduos com entretenimento e outros proveitos. O mundo passou a ser midiático e mediar pedagogicamente, nesse contexto, é uma grande incumbência para o professor.

O ciberespaço é um possível lócus de integração e articulação de todas as pessoas conectadas com tudo o que existe no espaço digital (KENSKI, 2012). Mas nem todos estão conectados e/ou aptos a participarem efetivamente dessa conexão, porque não dominam as novas tecnologias e o seu potencial. A escola e o professor, nesse contexto, devem cumprir a sua função de formar para a vida, e a vida, na sociedade atual, está imersa em novas tecnologias.

Pensadas em funçáo desse projeto, as novas tecnologias podem ser incorporadas pedagogicamente, aproximando professores e alunos de um 
mundo midiático. Isso significa superar um abismo existente entre o mundo exterior e o que acontece dentro da escola. É valorizar que por meio desses recursos, na era informacional, é possível aprender em qualquer tempo e em qualquer lugar, pois todos os espaços podem ser igualmente significativos.

A tecnologia é tudo que potencializa a ação humana. Trata-se de um recurso que, em si, não é bom nem ruim, mas os seus efeitos dependem da intencionalidade e da ação metodológica que será empregada. É indubitável que ainda se encontram muita resistência e receio em relação à utilização de novas tecnologias nas escolas, e é insensato não compreender o porquê disso.

A fim de que os alunos sejam preparados para a sociedade do conhecimento, a escola e os seus profissionais precisam refletir e mudar os seus métodos e técnicas por outros que sejam mais eficientes e eficazes (COUTINHO; LISBÔA, 2011). É preciso, ainda, planejar as oportunidades do processo de ensino-aprendizagem, a fim de que o arsenal de novas tecnologias coopere para o êxito pedagógico, de acordo com os objetivos educacionais. Como recurso, o uso de tecnologias precisa ser norteado por uma concepção.

Nesse sentido, professores e alunos precisam ser sensibilizados para a utilização consciente, criativa e dinâmica das novas tecnologias, utilizadas como meio de comunicação pedagógica, visando elevar a qualidade do ensino.

O objeto de investigação deste estudo, portanto, é o uso das novas tecnologias nos processos formativos educacionais, sob a perspectiva de professores. Os questionamentos que nortearam a execução desta pesquisa são:

- Quais são as percepçóes e experiências dos professores em relação às novas tecnologias e ao trabalho pedagógico?

- Quais são os desafios impostos aos espaços educativos diante desse novo paradigma?

- Que reconfiguraçóes precisam ocorrer nas escolas para atender às necessidades da sociedade tecnológica?

- Por que e como as novas tecnologias podem ser encaradas como potencializadoras e facilitadoras do processo de ensino-aprendizagem?

À luz disso, o objetivo geral da pesquisa é investigar e analisar a compreensão que professores têm sobre o uso das novas tecnologias nas escolas, de modo que, na primeira seção do trabalho, tecemos uma discussão teórica acerca da relaçáo entre educaçáo e novas tecnologias, seguida da explicitação da metodologia e do contexto de produção das informaçôes empíricas. $\mathrm{Na}$ terceira seção, analisamos e discutimos os dados coletados na pesquisa, 
desenvolvida com um grupo de professores de uma turma do Programa de Pós-Graduação Stricto Sensu em Educação da Universidade de Brasília (UnB). Os aspectos analisados - e que, portanto, se configuram como as principais categorias de análise deste estudo - são: a utilização no contexto escolar; formação (inicial ou continuada); obstáculos e vantagens identificados no seu uso.

Por fim, com as consideraçóes realizadas neste artigo espera-se que possamos repensar a perspectiva que a educaçáo, em relação com as novas tecnologias, assume nesse novo contexto, pois, dessa forma, estaremos refletindo sobre que configuração de formação os indivíduos precisam para a sua inserção no contexto de um mundo cada vez mais flexível, globalizado e conectado pelas novas tecnologias.

\section{Educaçáo e novas tecnologias}

$\mathrm{Na}$ aurora do dilúvio informacional, talvez uma meditação sobre o dilúvio bíblico possa nos ajudar a compreender melhor os novos tempos. Onde está Noé? $\mathrm{O}$ que colocar na arca? [...] O dilúvio informacional jamais cessará, não terá fim. Não há nenhum fundo sólido sob o oceano das informaçôes. Devemos aceitá-lo como nossa nova condiçáo. Temos que ensinar nossos filhos a nadar, a flutuar, talvez a navegar. (LÉVY, 2010).

A inserção da epígrafe logo no início deste trabalho se justifica por considerarmos que sua mensagem dialoga, coerentemente, com os nossos propósitos, ao definir como objeto de estudo o uso das novas tecnologias nos processos formativos educacionais.

O período que sucede o final da década de 90 é marcado pelo dilúvio a que o autor supracitado faz referência: a era da informação, alicerçada nos produtos e processos advindos dos avanços científico e tecnológico. $\mathrm{O}$ computador, a internet e as tecnologias digitais fizeram emergir um novo paradigma social, em que a relação do homem com o trabalho, com as pessoas e com o mundo, bem como seus comportamentos, pensamentos e sua cotidianidade, transformaram-se.

Tal processo de mudanças, no qual as tecnologias (sobretudo as novas) invadem e modificam a sociedade contemporânea, da qual o estudante faz parte, provoca a reflexáo sobre o modo de se fazer educação, dado que elas (as tecnologias) também estabelecem novas formas de acesso à infor- 
mação, novas relaçóes com o saber e com o conhecimento, novos estilos de raciocínio e aprendizagem, e desvelam que a escola perde a exclusividade no processo de construçáo do conhecimento.

É bem provável que o papel da escola e dos pais, como pontuou Lévy (2010), não seja o de ensinar os alunos e seus filhos a operar tecnicamente as novas tecnologias, uma vez que já nasceram entre elas. Mas, certamente, teremos que prepará-los para que flutuem e naveguem no oceano de informaçóes e se apropriem destas tecnologias de forma menos inocente, mais ativa, crítica e perspicaz, pois, o que surge na órbita dessas redes digitais, como profere o autor, é que seu uso é, ao mesmo tempo, um veneno e um remédio. Veneno aos que delas não participam e, mesmo participando, não conseguem ler e interpretar suas mensagens, bem como pelas formas de isolamento e de sobrecarga cognitiva, de dependência, de dominação, de exploração e de bobagem coletiva a que estão submetidos. Remédio aos que conseguem participar, socializar, se emancipar, se orientar e, portanto, se aliviam do ritmo desestabilizante e excludente dos turbilhóes informacionais.

Muitos dos nossos estudantes crescem/cresceram em ambientes altamente mediados pela tecnologia, sobretudo a audiovisual e a digital. A internet, os videogames, as imagens, os smartphones e seus aplicativos atraem de forma extraordinária a atenção desses nativos digitais, que desenvolvem uma grande habilidade para operar tais técnicas, captar e decifrar suas mensagens, além de dominar suas linguagens (SANCHO, 2006). Para Kenski (2012, p. 18), a educação possui duplo desafio nesse contexto: "Adaptar-se aos avanços das tecnologias e orientar o caminho de todos para o domínio e a apropriação crítica desses novos meios".

De tecnologias da informação e comunicação a ferramentas educativas, o computador, os celulares smartphones, dentre outros recursos digitais, se configuram à nossa ótica como um motor que engendra novas perspectivas pedagógicas. Por essa e pelas razóes seguintes, não podem ficar fora da escola: possuem múltiplos ambientes de aprendizagem, promovem a interação do sujeito com o objeto de estudo, possibilitam o desenvolvimento de metodologias ativas, dinamizam o processo de ensino-aprendizagem, possuem linguagens de interesse dos alunos, integram diferentes culturas (CASTELLS, 2001), propiciam melhor conhecimento e maior aprofundamento do conteúdo estudado (KENSKI, 2012), contribuem para o desenvolvimento da autonomia do indivíduo etc. 
É certo que a escola não escapa das tendências dessa sociedade tecnológica, que a desafia, todo instante, a construir novos espaços de conhecimento que sejam tão interativos, dinâmicos e possibilitadores de aprendizagens significativas como as ferramentas tecnológicas dos cotidianos dos alunos. Entretanto, é válido ressaltar que "as tecnologias, sozinhas, não educam ninguém” (KENSKI, 2012, p. 9). O uso das novas tecnologias, seja no espaço escolar ou nos espaços de vivência dos alunos, exige domínio e leitura crítica de quem as utiliza.

$\mathrm{Na}$ escola, a razão de sua utilizaçáo não deve ser outra senão a finalidade formativa, ou seja, a de possibilitar a efetivaçáo da aprendizagem ou a construção do conhecimento. Não é porque fazem parte do cotidiano dos estudantes ou porque acompanham as mudanças contemporâneas advindas do uso das redes, transformando as relaçóes com o saber (como enfatiza a autora), que as novas tecnologias devem se fazer presentes na sala de aula, mas sim pelos motivos já expostos. Isso demanda do professor habilidades pedagógicas específicas para que elas se constituam como uma ferramenta potencializadora e facilitadora do processo de construção da aprendizagem.

$\mathrm{Na}$ próxima seção, apresenta-se a metodologia utilizada no desenvolvimento da pesquisa e o contexto de produção das informaçóes empíricas. O caminho percorrido buscou dar respostas às questóes norteadoras deste estudo, que investiga a relação entre as novas tecnologias e a escola, analisando a compreensão que professores têm sobre a utilização das novas tecnologias no ambiente escolar.

\section{Metodologia e o contexto de produção das informaçóes empíricas}

A pesquisa, de natureza qualitativa, se estrutura em duas etapas: bibliográfica e empírica. Na primeira, não dissociada da segunda, buscou-se tecer uma discussão teórica acerca da relação entre educação e novas tecnologias. Na segunda, foi desenvolvido, no primeiro semestre do ano 2018, um estudo com professores matriculados na disciplina Inovaçáo e Novas Tecnologias nos processos formativos, ofertada pelo Programa de Pós-Graduação Stricto Sensu em Educação da UnB, na modalidade profissional.

O universo da pesquisa, constituído por esse grupo de professores, constitui-se por sete professoras e dois professores, sendo todos profissionais atuantes na Educação Básica do Distrito Federal - DF. Cumpre destacar que, para preservar a identificaçáo e manter o anonimato dos professores 
participantes da pesquisa, seus nomes foram substituídos por PROFESSOR A, B, C, D, E, F, G, H, I.

O instrumento metodológico utilizado na coleta dos dados e das informaçóes empíricas foi o questionário, aplicado via Google Formulários, com questôes objetivas e subjetivas relacionadas às novas tecnologias e à educação, quais sejam: a utilização no contexto escolar; formação (inicial ou continuada); e obstáculos e vantagens que identificam no seu uso. Tais aspectos, portanto, se configuraram nas principais categorias de análise desta investigação.

\section{Análise e discussão dos dados: as vozes dos professores acerca do uso das novas tecnologias nas escolas}

Do grupo pesquisado (nove docentes), a maioria relatou trabalhar na rede pública de ensino do DF. No que diz respeito ao tempo em que atuam como docentes, cinco responderam que têm entre 1 e 10 anos de experiência, três afirmaram ter entre 11 e 20 , e um declarou ter entre 21 e 30 anos de experiência.

Quando questionados se concordavam com a afirmação contida em duas frases, de que a escola não pode ignorar ou hostilizar as tecnologias e de que, pelo fato de fazerem parte do cotidiano dos estudantes fora do ambiente escolar e serem uma linguagem mais próxima à realidade dos alunos, elas também deveriam estar presentes dentro da escola, todos os sujeitos da pesquisa declararam estarem de acordo. Sobre isso, também pontua Demo (1991) que a escola não pode ficar à margem das mudanças que as tecnologias vêm impondo à nossa sociedade. Percebeu-se pelos argumentos que os professores compreendem que o novo paradigma técnico-econômico tem implicaçôes na estruturação da sociedade, conforme excerto a seguir:

O surgimento de novas tecnologias na sociedade altera, de maneira significativa, as formas como as pessoas relacionam-se, informam-se e comunicam-se. E essas tecnologias ampliam, cada vez mais, a velocidade e a circulação de informações, influenciando na organização da sociedade. Neste sentido, bancos, supermercados, escolas e outros espaços têm, para manterem-se conectados com esse mundo, que acompanhar essa evolução das tecnologias. (PROFESSOR A, 2018, s.p). 
Diante dessa metamorfose social propiciada pelo avanço tecnológico, os entrevistados reconhecem que a escola não pode ter uma postura de indiferença, mantendo métodos e recursos arcaicos. Não promover a inserção dos novos recursos e da gama de possibilidades pedagógicas que eles possuem comprometeria a comunicação/integração entre o mundo e a escola. Essa questáo pode ser corroborada pelas afirmativas de três professores, como veremos abaixo:

Acredito que já náo podemos nos dar ao luxo de ignorar a realidade que está posta: nossos alunos hoje são altamente tecnológicos e a escola não pode fingir que pode continuar ensinando como faz há dois séculos. (PROFESSOR D, 2018, s.p).

Acredito que as tecnologias devem fazer parte do sistema educacional no qual o educando está presente como uma extensáo do mundo para a escola e da escola para o mundo. (PROFESSOR B, 2018, s.p).

Não dá mais para continuar com um ensino tradicional, desmotivador, repetitivo e maçante, o qual acaba sendo um dos momentos mais desinteressantes dos jovens - e adultos também - do século XXI. (PROFESSOR F, 2018, s.p).

Tal como esclarecem Belloni (1991), Kenski (2012), Sancho (2006) e Castells (2001), as tecnologias possibilitam a interação, a integração e geram novos modos de pensar e sentir, e, por consequência, de aprender. À luz disso, outro aspecto que merece destaque é a percepção dos entrevistados de que a inclusão das tecnologias nos processos formativos pode viabilizar o êxito do aprendizado, e até reconhecem a importância de se comprometerem nesse sentido. As referências a seguir ratificam essa reflexão: a) "as tecnologias devem estar inseridas no planejamento do professor como recurso facilitador do processo de ensino e aprendizagem" (PROFESSOR G, 2018, s.p); b) "a tecnologia bem utilizada contribui para o sucesso educacional” (PROFESSOR I, 2018, s.p); c) "precisamos utilizar esses recursos e instrumentos para facilitar a aprendizagem” (PROFESSOR E, 2018, s.p, grifo nosso).

Alguns participantes da pesquisa demonstraram inquietação quanto à forma de utilização das tecnologias no contexto educacional, nos levando a refletir que o uso de recursos tecnológicos por si só pode não possibilitar a construção do conhecimento, se o seu emprego náo estiver respaldado por uma intencionalidade pedagógica, como abordado na seção anterior. 
Concordo que deve fazer parte da escola, no entanto, preocupo-me muito quando utilizada como produto e náo como processo. (PROFESSOR A, 2018, s.p).

Toda ferramenta tecnológica precisa ser pensada como processo e náo como produto, para que não se torne algo mecanizado e, sim, formativo com o processo de reflexão. (PROFESSOR C, 2018, s.p).

Quando interrogados se já participaram de alguma formação, seja ela inicial ou continuada, relacionada ao uso das novas tecnologias na escola, $67 \%$ afirmaram que sim e $33 \%$ afirmaram que não. Esses resultados se configuram como dados extremamente preocupantes, pois, se é notória a importância da inclusão tecnológica (com intencionalidade pedagógica) no ambiente escolar, por conta da conjuntura social que demanda cada vez mais afinidade com as tecnologias, os cursos de formação de professores deveriam inclui-las em seus currículos e desenvolver práticas educativas que contemplem essa temática. Ademais, os professores que não tiveram estudo sobre isso, reconhecendo sua relevância para a formação crítica e cidadã do indivíduo, devem buscar suprir essas lacunas por meio de formaçóes continuadas.

Ainda que o grupo pesquisado, predominantemente, tenha participado de formação que aborde a questão da tecnologia no contexto educacional, a maioria afirma que não se sente habilitada para o domínio tecnológico e suas linguagens a serviço da educação. O principal motivo destacado para essa insegurança e despreparo é a volatilidade e versatilidade da tecnologia, que exige formação, aprendizagem e investimento contínuo/permanente (COUTINHO e LISBÔA, 2011). Muitas tecnologias entram em obsolescência antes mesmo de dominarmos suas técnicas. Um comentário que resume convenientemente esse raciocínio é:

Não me sinto preparada, embora tenha passado por capacitação, porque a linguagem digital é dinâmica e mutável, o que implica em capacitação e autorreflexão constante sobre o fazer docente. (PROFESSOR G, 2018, s.p).

A respeito da utilização de novas tecnologias em sala de aula, um professor afirmou não utilizar, demonstrando resistência ou insegurança para empregá-las. E os demais, ou seja, a maioria, declarou incluir variadas tecnologias na sua atividade pedagógica. Esse indício é interessante, pois mesmo a maioria não se sentindo preparada quanto ao domínio tecnoló- 
gico, demonstra-se pretensão e esforço em introduzi-las em sala de aula (e isso, aos poucos, pode lhes trazer mais confiança e ajudar a superar a insegurança), embora reconheça que, além da má-formação, outros obstáculos também dificultam tal apropriação: carência de equipamentos apropriados, de infraestrutura ou de manutenção dos produtos tecnológicos, enfim, de adequadas condiçóes de trabalho.

Os professores que declararam utilizar essas tecnologias, e até mesmo elencaram tecnologias possíveis de serem aplicadas em sala de aula, vislumbraram algumas habilidades que podem ser desenvolvidas no processo educativo, e ainda salientaram justificativas didáticas para o emprego dessas ferramentas no contexto educacional: a) "A construção da escrita coletiva de um documento, on-line ou não, [...] pois, favorece o trabalho colaborativo" (PROFESSOR B, 2018, s.p); b) "Quiz (Perguntas e Respostas objetivas), armazenando os acertos e os erros de cada acadêmico, o que pode ser retomado pelo professor posteriormente dentro de um processo avaliativo formativo" (PROFESSOR I, 2018, s.p). Além disso, ainda apontaram outras possibilidades pedagógicas mediadas pela tecnologia, tais como:

a gameficação, devido ao potencial de engajamento que os jogos exercem sobre as pessoas, é uma forma leve e atraente de envolver os alunos por meio da tecnologia. Outra proposta poderia ser tentar usar as redes sociais, talvez um grupo do Facebook com conteúdos interessantes, pois os alunos dominam a ferramenta e sua linguagem. (PROFESSOR C, 2018, s.p).

Por fim, vale revelar as "vozes" dos professores em relação às vantagens do uso das novas tecnologias nas práticas educativas escolares. Nesse aspecto, as questóes evidenciadas foram: flexibilidade, engajamento, dinamismo, atração e múltiplas possibilidades que são abertas por esses recursos. Essas percepções podem ser contempladas nessa afirmação:

O uso dessas tecnologias abre várias possibilidades de aprendizagem, de maneira mais lúdica, dinâmica, atrativa, por meio das imagens, sons e um vasto campo de informaçôes, podendo também ser interativa. (PROFESSOR E, 2018, s.p).

Pela observação dos aspectos analisados, é oportuno pontuar que, para Kenski (2012) e para nós, as Tecnologias da Informação e Comunicação - TICs - e o ciberespaço se configuram como um novo espaço pedagó- 
gico que oferece inúmeras possibilidades e desafios para o desenvolvimento cognitivo, humano, social e afetivo dos indivíduos, dentre eles alunos e professores. Se apropriar adequadamente de tais ferramentas no contexto educacional possibilita a alteração qualitativa das dinâmicas intrínsecas ao processo de ensino e aprendizagem. Para tanto, as escolas necessitam redefinir suas funções educativas e sociais frente às necessidades da sociedade tecnológica, bem como dispor de profissionais capacitados, práticas educativas e espaços adequados, equipamentos apropriados, dentre outras questóes e condiçóes que favoreçam o desenvolvimento do seu trabalho, sobretudo, mediado pelas novas tecnologias.

\section{Consideraçóes finais}

O trabalho, ao investigar e analisar a compreensão que professores têm sobre a utilização das novas tecnologias no ambiente escolar, procurou evidenciar que o novo paradigma técnico-econômico que impacta diferentes esferas da vida social, também afeta a escola e lhe impóe a necessidade de inovação, mudanças - intrínsecas ao processo de avanço tecnológico - e redefinição do seu formato e papel frente às demandas de um mundo cada vez mais flexível, fluido, globalizado e conectado por tais tecnologias.

Pelas vozes dos professores, verificou-se que, embora haja desafios, as possibilidades e potencialidades tecnológicas de melhorias nos processos formativos são vastas e promissoras, sobretudo na superação do formato tradicional de ensino e aprendizagem, já arraigado há séculos no país. Tais sujeitos evidenciaram, ainda, a importância da incorporação das novas tecnologias e de métodos apropriados para fazer frente às demandas do mundo midiático.

No contexto atual de conectividade, interação e dinamismo, propiciado pelas novas tecnologias, demanda-se que estas sejam aproximadas das atividades pedagógicas, para que o espaço escolar esteja em sincronia com o mundo, que está cada vez mais tecnológico. Se as tecnologias potencializam a ação humana em diferentes sentidos, também em âmbito pedagógico, elas podem ser empregadas de acordo com o desenho das oportunidades de ensino-aprendizagem traçado pelo professor. Introduzir as tecnologias no ambiente educacional já é um avanço para que os professores se sintam mais confortáveis com a sua presença neste contexto e, aos poucos, sintam-se mais confiantes e mais seguros em relação à sua utilização e às melhoras funcionais que estas podem trazer para o trabalho pedagógico. 
Contudo, e ainda em tempo, esclarecemos que nossas colocaçóes não são ingênuas a ponto de acreditar que o uso de artefatos tecnológicos, por si só, deslinde os problemas que assolam o ensino da escola pública brasileira. Mas, por meio deles, de políticas educacionais acertadas e da competência intelectual e política do professor (SAMPAIO e LEITE, 2013), acreditamos numa renovação que afetará o coração da escola, proporcionando aos alunos uma "aprendizagem sólida que lhes permita enfrentar criticamente as mudanças aceleradas da atual sociedade da informação e do conhecimento [...], bem como transitar com autonomia por essa realidade, sem deixar-se enganar por ela" (CARBONELL, 2002, p. 16).

\section{Referências}

BELLONI, Maria Luíza. Educação para a mídia: missão urgente da escola. Comunicação e Sociedade - Revista de Estudos de Comunicação, s.n., v. 10, n. 17, p. 33-45, ago. 1991.

CARBONELL, Jaume. A aventura de inovar: a mudança na escola. Porto Alegre: Artmed Editora, 2002.

CARVALHO, Olgamir Francisco. Educação e formação profissional-trabalho e tempo livre. Brasília: Plano Editora, 2003.

CASTELLS, Manuel. La galáxia internet. Barcelona, Plaza y Janés (Areté), 2001.

COUTINHO, Clara; LISBÔA, Eliana. Sociedade da informação, do conhecimento e da aprendizagem: desafios para a educação no século XXI. Revista de Educação, vol. 18, n. 1, 2011, p. 5-22.

DEMO, Pedro. Educação e desenvolvimento: algumas hipóteses de trabalho frente à questão tecnológica. Revista Tempo Brasileiro. Rio de Janeiro, n. 105, p. 149-170, abr-jun, 1991.

KENSKI, Vani Moreira. Educação e Tecnologias: o novo ritmo da informação. 8. ed. Campinas, SP: Papirus, 2012.

LÉVY, Pierre. Cibercultura. 3. ed. São Paulo: Editora 34, 2010.

SAMPAIO, Marisa Narcizo; LEITE, Lígia Silva. Alfabetização tecnológica do professor. 10. ed. Petrópolis, RJ: Vozes, 2013. 
SANCHO, Juana Maria. De tecnologias da informação e comunicação a recursos educacionais. In: SANCHO, Juana Maria et al. Tecnologias para transformar a educação. Porto Alegre: Artmed, 2006.

Recebido em: 26 ago. 2019.

Aceito em: 20 out. 2019. 